\title{
Article \\ Interfacial Mass Transfer in Trichloroethylene/Surfactants/ Water Systems: Implications for Remediation Strategies
}

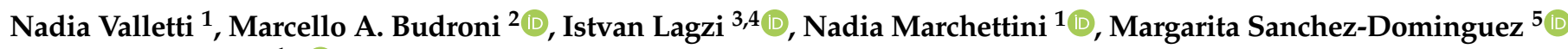 \\ and Federico Rossi ${ }^{1, *(D)}$ \\ 1 Department of Earth, Environmental and Physical Sciences-DEEP Sciences, University of Siena, \\ Pian dei Mantellini 44, 53100 Siena, Italy; nadia.valletti@student.unisi.it (N.V.); \\ nadia.marchettini@unisi.it (N.M.) \\ 2 Department of Chemistry and Pharmacy, University of Sassari, Via Vienna 2, 07100 Sassari, Italy; \\ mabudroni@uniss.it \\ 3 MTA-BME Condensed Matter Physics Research Group, Budapest University of Technology and Economics, \\ Budafoki ut 8, 1111 Budapest, Hungary; lagzi.istvan.laszlo@ttk.bme.hu \\ 4 Department of Physics, Budapest University of Technology and Economics, Budafoki ut 8 , \\ 1111 Budapest, Hungary \\ 5 Grupo de Química Coloidal e Interfacial Aplicada a Nanomateriales y Formulaciones, \\ Centro de Investigación en Materiales Avanzados, S.C. (CIMAV), Unidad Monterrey, Alianza Norte 202, \\ Parque de Investigación e Innovación Tecnológica, Apodaca 66628, Mexico; margarita.sanchez@cimav.edu.mx \\ * Correspondence: federico.rossi2@unisi.it; Tel.: +39-0577232215
}

check for updates

Citation: Valletti, N.; Budroni, M.A.; Lagzi, I.; Marchettini, N.; Sanchez-Dominguez, M.; Rossi, F. Interfacial Mass Transfer in Trichloroethylene/Surfactants/Water Systems: Implications for Remediation Strategies. Reactions 2021, 2, 312-322. https://doi.org/ $10.3390 /$ reactions 2030020

Academic Editors: Ioannis V. Yentekakis and Dmitry Yu. Murzin

\section{Received: 8 July 2021}

Accepted: 30 August 2021

Published: 3 September 2021

Publisher's Note: MDPI stays neutral with regard to jurisdictional claims in published maps and institutional affiliations.

Copyright: (c) 2021 by the authors. Licensee MDPI, Basel, Switzerland. This article is an open access article distributed under the terms and conditions of the Creative Commons Attribution (CC BY) license (https:/ / creativecommons.org/licenses/by/ $4.0 /)$.

\begin{abstract}
The fate of dense non-aqueous phase liquids (DNAPLs) in the environment and the consequential remediation problems have been intensively studied over the last 50 years. However, a scarce literature is present about the mass transfer at the DNAPL/water interface. In this paper, we present a fast method for the evaluation of the mass transfer performance of a surfactant that can easily be employed to support an effective choice for the so-called enhanced remediation strategies. We developed a lab-scale experimental system modelled by means of simple ordinary differential equations to calculate the mass transfer coefficient $(K)$ of trichloroethylene, chosen as representative DNAPL, in the presence and in the absence of two ethoxylated alcohols belonging to the general class of Synperonic surfactants. Our findings revealed that it exists an optimal surfactant concentration range, where $K$ increases up to $40 \%$ with respect to pure water.
\end{abstract}

Keywords: trichloroethylene; kinetic model; mass transfer coefficient; green surfactant; surfactant co-solvent flushing; poly-oxyethylene alcohol

\section{Introduction}

Trichloroethylene (TCE) belongs to the dense non-aqueous phase liquids (DNAPLs) and is listed as a carcinogenic contaminant by the International Agency for Research on Cancer (IARC) [1]. Because of its physical-chemical properties, in particular low aqueous solubility and high density, TCE enters the saturated zone of the subsurface as a free phase, leaving behind a tail of discrete ganglia trapped by capillary forces, causing long-term contamination of soils and groundwaters [2,3]. Classical remediation techniques, like pumpand-treat $(\mathrm{P} \& \mathrm{~T})$, are not quite effective for the removal of the stratified contaminant $[4,5]$; therefore, the surfactant/co-solvent flushing method, where a mixture of chemicals is employed to increase the extraction yield [6-8], is becoming more and more popular. Surfactants are being employed also for improving the performances of TCE mineralization techniques, when used in the water phase to oxidate trichloroethylene to unharmful products such as $\mathrm{CO}_{2}, \mathrm{H}_{2} \mathrm{O}$, and $\mathrm{HCl}$, according to the half-reaction

$$
\mathrm{C}_{2} \mathrm{HCl}_{3}+4 \mathrm{H}_{2} \mathrm{O} \rightarrow 2 \mathrm{CO}_{2}+9 \mathrm{H}^{+}+3 \mathrm{Cl}^{-}+6 \mathrm{e}^{-} .
$$


The most popular oxidants in these processes are ozone, permanganate, persulphate, and the Fenton's system [9]. Other degradation techniques consist of reduction through zero-valent iron nanoparticles [10] and the catalytic oxidation in gas-phase (either with metal-supported or unsupported catalysts) [11-14].

Surfactants have essentially a two-fold role in remediation and degradation applications, namely enhancing the solubilisation of the TCE in the water bulk and increasing the kinetics of the process by bringing the oxidant into closer contact with the substrate [15-19]. In fact, surfactants are able to form a great variety of self-assembling structures in solution (micelles, vesicles, coacervates, liquid crystals, etc.), all of which share the characteristic of compartmentalisation between polar and non-polar regions, with defined boundary interfaces [20]. The presence of hydrophobic sites in water solutions is the key factor that promotes a greater dispersion of organic molecules in the bulk, eventually by forming microemulsions [8]. The so-called palisade layer (the most external region of micelles where the polar heads point towards the water) is, instead, the place where the organic molecules in the micellar core come into closer contact with ionic species (permanganate, persulphate, hydroxyl, etc.) responsible for the degradation of the pollutants. Generally, the rational choice of a surfactant for the enhanced degradation of DNAPLs is a trade-off among several factors, including extraction yields, economic costs, and environmental impacts of the surfactant itself. For the in situ remediation, the mass transfer rate between the contaminant pool and the water phase is also of paramount importance. In fact, the oxidation reactions involve the action of many free radical species and the kinetics per se is quite fast; therefore, the slow step in the whole degradation process is generally the transfer rate of the contaminants from the pools to the water phase [17].

In this paper, we present a fast method for the evaluation of the mass transfer performance of a surfactant that can easily be employed to support an effective choice for enhanced remediation strategies. We developed a lab-scale experimental system modeled by means of simple ordinary differential equations. The output fitting parameter is the mass transfer constant measured in $\mathrm{mm} / \mathrm{s}$, which accounts for the average velocity at which a molecule of pollutant pass from the organic to the water phase (or the micellar pseudo phase in case surfactants are present). As an example, we compared the efficiency of two ethoxylated alcohols belonging to the general class of Synperonic surfactants that we recently demonstrated to be effective for increasing the solubility of TCE $[7,8]$. Synperonic compounds have the general formula $\mathrm{R}\left(-\mathrm{O}-\mathrm{CH}_{2}-\mathrm{CH}_{2}-\right)_{n}-\mathrm{OH}$ where $\mathrm{R}$ is the hydrophobic alkyl chain linked to a variable number of ethylene oxide units. The employed surfactants are the Synperonic 91/5 (SYN91/5, R = 9-11, $\mathrm{n}=5$ ) and Synperonic 91/10 (SYN91/10, $\mathrm{R}=9-11, \mathrm{n}=10$ ) having a hydrophilic lyophilic balance (HLB) values of 12.54 and 15.28 and a critical micellar concentration $(\mathrm{CMC})$ of $7.94 \times 10^{-4} \mathrm{M}$ and $5.5 \times 10^{-4} \mathrm{M}$, respectively $[7,8]$.

\section{Theoretical Approach}

Mass transfer at the interface of two miscible and/or slightly miscible liquids is in general a complex mechanism that involves diffusive and advective phenomena [21]. Molecular diffusion, double diffusion [22] and cross-diffusion [23-25] can trigger hydrodynamic instabilities (fingers, plumes, waves, etc.) that generally enhance the mixing of the liquids but are difficult to decouple in order to understand the single contributions to the global dynamics. When reactions are present at the interface, complexity increases further $[26,27]$.

When diffusion does not drastically change the density or the surface tension of one of the two liquids, simpler approaches are possible; for example, starting from the seminal Epstein \& Plesset equation [28], originally designed for a gas bubble dissolution, several models have been developed to measure the mass transfer in terms of the diffusion coefficient (measured in $\mathrm{cm}^{2} \mathrm{~s}^{-1}$ ) of a species $i$ in the presence of a concentration gradient $\left(\nabla C_{i}\right)$. The Epstein \& Plesset equation is used to describe the dissolution dynamics of liquid droplets dispersed in a bulk [29-32]. When a finite concentration difference $\left(\Delta C_{i}\right)$ 
is considered in the place of a gradient, the mass transfer can be described by ordinary differential equations (ODEs). Experimental conditions to meet this requirement can be easily obtained on a lab-scale. Figure 1 sketches the basic features of the batch reactor used in our experiments. A small volume of TCE $(\sim 0.5 \mu \mathrm{L})$ is poured at the bottom of a spectrophotometric cuvette, pre-filled either with pure water or with surfactant solutions containing SYN91/5 or SYN91/10 at different concentrations. The bulk is continuously stirred at a speed that ensures a homogeneous distribution of the dissolved TCE in the aqueous solution but does not perturb the TCE/water interface. Because of the surface tension at the interface, the volume of TCE tends to assume a spherical shape; the use of quartz cuvette helps to reduce the contact angle between the TCE drop and the bottom of the reactor, thus reducing the deviation from a perfect sphere.

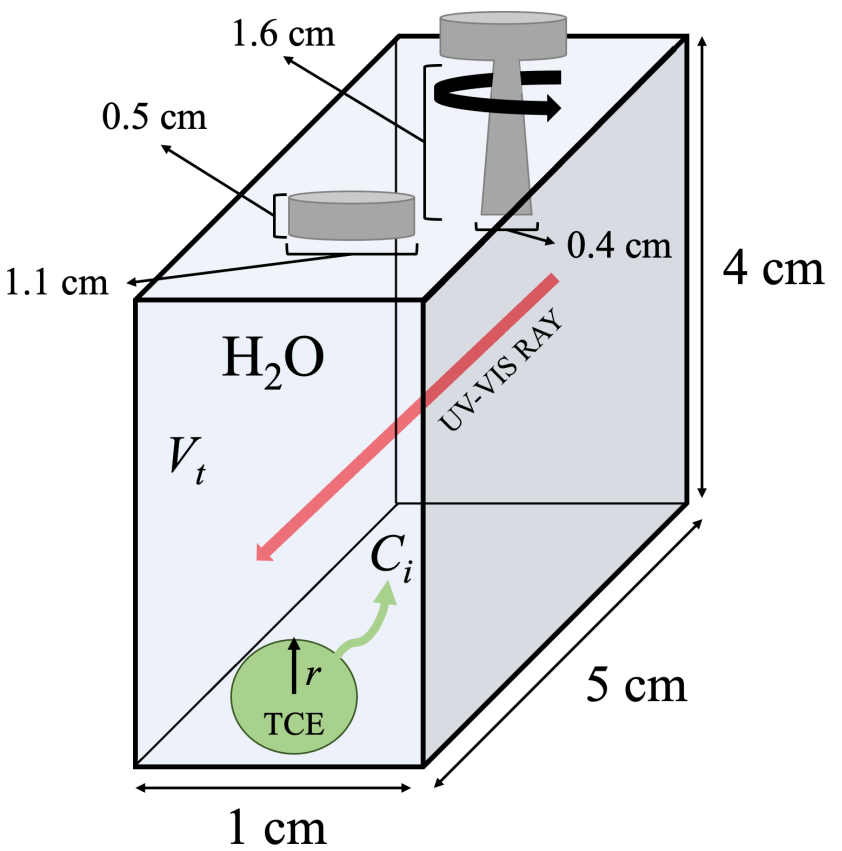

Figure 1. Experimental setup used for the mass transfer from a pool of TCE into an aqueous solution; $r$ is the radius of a TCE drop (initial radius $0.5 \mathrm{~mm}), V_{t}$ is the total volume of the aqueous phase $(18 \mathrm{~mL}$ ), and $C_{i}$ is the concentration of the TCE dissolved in the bulk phase; $C_{i}$ is spectrophotometrically monitored in time (sampling time $600 \mathrm{~s}$ ).

If $A=4 \pi r^{2}$ (with $r$ being the TCE droplet radius) is the interfacial area between the two liquids, the flux per unit area $N_{i}$ can be described by a first-order mass transfer equation [33]:

$$
N_{i}=\frac{1}{A} \frac{d n_{i}}{d t}=K\left(C_{s}-C_{i}\right),
$$

where $n_{i}$ indicates the amount of substance $(\mathrm{mol})$ of the species $i, C_{i}(\mathrm{M})$ is the molar concentration of the species $i$ in the bulk solution, $C_{S}(\mathrm{M})$ is the bulk saturation concentration of $i$, and $K$ is the mass transfer coefficient.

Equation (2) can be rewritten as:

$$
\frac{d C_{i}}{d t} V_{t}=A K\left(C_{s}-C_{i}\right),
$$

where $V_{t}$ is the bulk total volume. The driving force of mass transfer is obviously the concentration difference $\left(C_{s}-C_{i}\right)=\Delta C_{i}$.

Dividing both sides of the Equation (3) by $V_{t}$ gives the following equation:

$$
\frac{d C_{i}}{d t}=a K\left(C_{s}-C_{i}\right),
$$


with

$$
a=\frac{A}{V_{t}},
$$

where $a\left(\mathrm{~mm}^{-1}\right)$ is the ratio between the droplet surface $\left(\mathrm{mm}^{2}\right)$ and the total volume of the solution $\left(\mathrm{mm}^{3}\right)$ and $r$ is the droplet radius $(\mathrm{mm})$; in this way, $K$ has the units of $\mathrm{mm} \mathrm{s}^{-1}$.

Because of TCE chemical-physical properties (low solubility in water, high vapor pressure, high Henry's law constant), a little amount of TCE may evaporate and leave the system [34]. For this reason, a volatilization term has been included in the mass balance. The Equation (4) becomes:

$$
\frac{d C_{i}}{d t}=a K\left(C_{s}-C_{i}\right)-K_{v} C_{i},
$$

$K_{v}$ being the volatilization coefficient $\left(\mathrm{s}^{-1}\right)$ for TCE.

During TCE droplet dissolution, the radius $r$ decreases. Considering this phenomenon, the change of the TCE mass in the droplet is proportional to the flux $\left(N_{i}\right)$ of molecules across the interface TCE $/ \mathrm{H}_{2} \mathrm{O}$

$$
-\frac{d}{d t}\left(\frac{\rho_{T C E}}{M M_{T C E}} V_{T C E}\right)=A N_{i},
$$

where $\rho_{T C E}$ is TCE density, $M M_{T C E}$ is the TCE molecular mass, and $V_{T C E}$ is the TCE droplet volume. Considering Equation (3) and assuming that the droplet keeps a spherical shape for the whole dissolution process, the variation of the radius in time can be expressed as [35]

$$
-\frac{d}{d t}\left(C_{s t} \frac{4}{3} \pi r^{3}\right)=4 \pi r^{2} K\left(C_{s}-C_{i}\right),
$$

where $\mathrm{C}_{s t}$ is the concentration of pure TCE $(11.11 \mathrm{M})$. Rearranging Equation (8), the change of $r$ during TCE dissolution, linearly related to $C_{i}$, becomes

$$
\frac{d r}{d t}=-K \frac{C_{s}-C_{i}}{C_{s t}} .
$$

Note that, when $C_{i} \ll C_{s}, C_{i}$ increases and $r$ decreases linearly with time, respectively. Coupled Equations (6) and (9) describe the kinetics of the mass transfer across the interface in the system TCE $/ \mathrm{H}_{2} \mathrm{O}$ (or TCE/SYN91/X/H $\mathrm{H}_{2} \mathrm{O}$ ) when a homogeneous distribution of the dissolved TCE in the aqueous solution is considered and a spherical shape of the droplet is maintained for the whole dissolution process. Their integration and fitting to the experimental data allow one to obtain the parameters $K$ and $K_{v}$.

\section{Materials and Methods}

Synperonic 91/5 (SYN91/5, Polyoxyethylene(5) C9-C11 alcohol, density $0.978 \mathrm{~g} / \mathrm{cm}^{3}$ ) and Synperonic 91/10 (SYN91/10, Polyoxyethylene(10) C9-C11 alcohol, density $0.998 \mathrm{~g} / \mathrm{cm}^{3}$ ) surfactants were provided by Croda International (UK) and the chemical structures are reported in Figure 2. TCE (analytical grade $>99.5 \%$ ) was purchased from Sigma-Aldrich (St. Louis, MO, USA). All experiments were performed in ultra-pure water with resistivity $>1 \mathrm{M} \Omega \mathrm{cm}$. The Synperonic solutions at different concentrations were prepared by dilution from stock solutions.

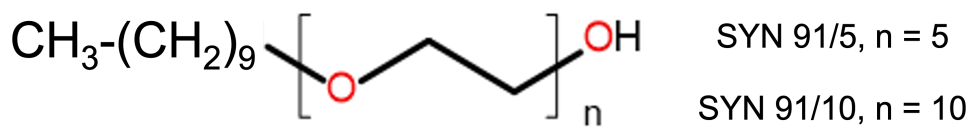

Figure 2. Chemical structure of the surfactants.

A series of batch experiments were performed using quartz cuvettes with path length $5 \mathrm{~cm}(1 \times 5 \times 5 \mathrm{~cm})$ at $23^{\circ} \mathrm{C}$. In order to keep the bulk homogeneous, the system was stirred with a home-made stirring system for the whole duration of the measurements, performed 
by means of a UV-VIS spectrophotometer (Agilent 8530). The total volume of the solutions for all the experiments was $18 \mathrm{~mL}$. TCE concentration was monitored by measuring the absorbance at $\lambda=230 \mathrm{~nm}$ following a calibration procedure. At the beginning of each experiment, $0.5 \pm 0.06 \mu \mathrm{L}$ of TCE were placed in the bottom of the cuvette using a $5 \mu \mathrm{L}$ glass syringe.

Images of the dissolving droplet were acquired with a CMOS camera Pixelink PLD755CU (Pixelink Inc., Ottawa, Canada) at $1 \mathrm{fps}$ and were analyzed by means of the software ImageJ [36]. To estimate the parameters $K$ and $K_{v}$, the experimental data were fitted with the Levenberg-Marquardt algorithm [37,38] by integrating Equations (6) and (9) with CO.PA.SI. software [39].

TCE saturation concentrations $\left(C_{s}\right)$ in Synperonic $91 / 5$ and $91 / 10$ solutions were previously measured by Intiso et al. [7] and Garza-Arévalo et al. [8] and are reported in Table 1. $C_{s}$ were determined by consecutive additions of TCE to surfactant solutions, followed by vigorous shaking. The last volumetric addition of TCE before macroscopic demixing of the solutions was used to calculate $C_{s}$. At the thermodynamic equilibrium, for a given temperature, stirring did not affect $C_{s}$.

Table 1. [SYN91/5] and [SYN91/10] tested and the related $C_{S}$ values.

\begin{tabular}{ccc}
\hline System & SYN (M) & $\boldsymbol{C}_{\boldsymbol{s}} \mathbf{( M )}$ \\
\hline $\mathrm{H}_{2} \mathrm{O}$ & - & $(9.74 \pm 0.03) \times 10^{-3}$ \\
\hline & $1 \times 10^{-4}$ & $(9.74 \pm 0.05) \times 10^{-3}$ \\
& $1 \times 10^{-3}$ & $0.020 \pm 0.001$ \\
SYN91/5 [7,8] & 0.01 & $0.022 \pm 0.002$ \\
& 0.05 & $0.022 \pm 0.001$ \\
& 0.08 & $0.022 \pm 0.003$ \\
& 0.10 & $0.022 \pm 0.003$ \\
& 0.20 & $0.047 \pm 0.002$ \\
SYN91/10 [8] & 0.30 & $0.067 \pm 0.002$ \\
\hline & $1 \times 10^{-4}$ & $(9.74 \pm 0.04) \times 10^{-3}$ \\
& 0.01 & $0.04 \pm 0.03$ \\
& 0.05 & $0.15 \pm 0.01$ \\
& 0.08 & $0.26 \pm 0.01$ \\
& 0.10 & $0.33 \pm 0.02$ \\
& 0.15 & $0.45 \pm 0.01$ \\
& 0.20 & $0.64 \pm 0.04$ \\
\hline
\end{tabular}

\section{Results}

Figure 3a shows a typical time-series of a TCE droplet dissolution in pure water at $T=23{ }^{\circ} \mathrm{C}$ and $2010 \mathrm{rpm}$. [TCE] $\left(C_{i}\right)$ increases in the bulk up to $\sim 10,000 \mathrm{~s}$ where it reaches a maximum at $\sim 3 \times 10^{-4} \mathrm{M}$, corresponding to the full dissolution of $0.5 \mu \mathrm{L}$ of TCE in $18 \mathrm{~mL}$ of water. After the complete dissolution of the droplet, a certain volatilization from the bulk takes place and [TCE] decreases with time. Fitting of experimental data by means of Equations (6) and (9) (as an example, Figure $3 \mathrm{~b}$ reports the fitting of the pre-maximum time-series) allowed for estimating the parameters $K \sim 1.7 \times 10^{-2} \mathrm{~mm} \mathrm{~s}^{-1}$ and $K_{v} \sim 6.0 \times 10^{-5} \mathrm{~s}^{-1}$. Figure $3 \mathrm{c}$ reports a series of snapshots of the TCE droplet taken during the dissolution process, as it can be seen that the approximation of the droplet shape to a sphere holds up well to almost the end of the process. This is also confirmed by the time-series of the droplet radius, as extracted from the experimental snapshots, reported in Figure 3d, which shows a linear decrease in time when $C_{i} \ll C_{s}$, as predicted by Equation (9). 

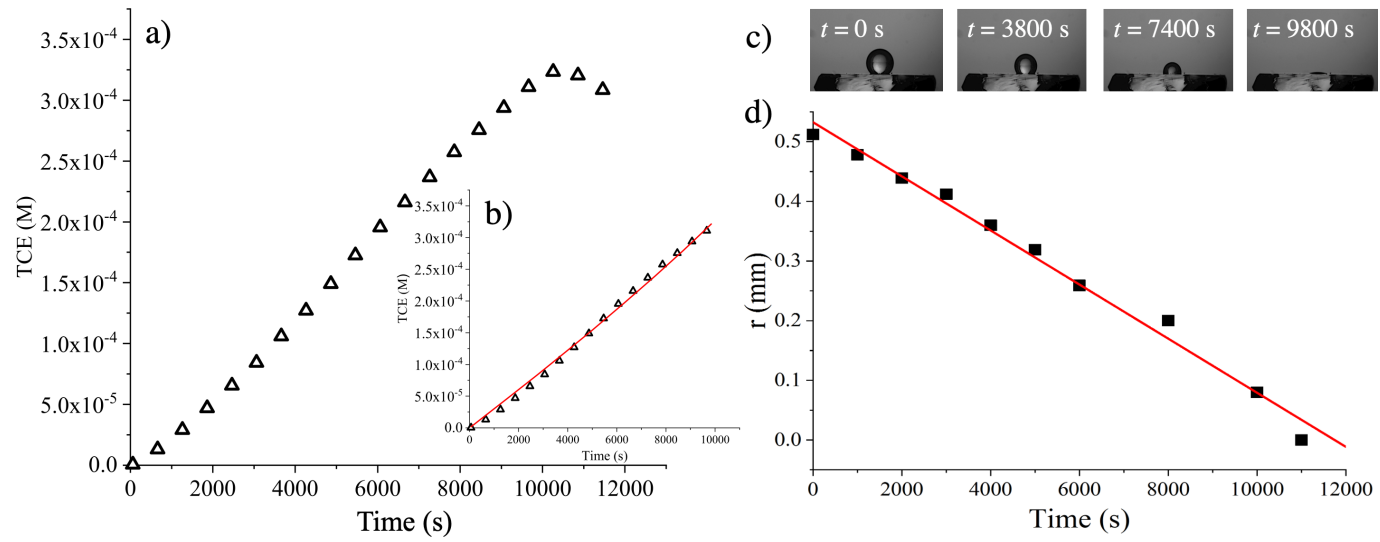

Figure 3. Experimental results in pure water. (a) Change of [TCE] in the bulk during an experiment in pure water at $T=23{ }^{\circ} \mathrm{C}$ and $2010 \mathrm{rpm}$; (b) fitting of the experimental data by means of Equations (6) and (9) (solid red line); (c) snapshots of the dissolution process; (d) fitting of the droplet radius, by means of Equations (6) and (9) (solid red line). The radius of the droplet was measured from the experimental snapshots.

The dependence of mass transfer coefficient on stirring rate has been evaluated at $T=23^{\circ} \mathrm{C}$ in pure water. Figure 4 and Table A1 in Appendix A report the corresponding $K$ and $K_{v}$.

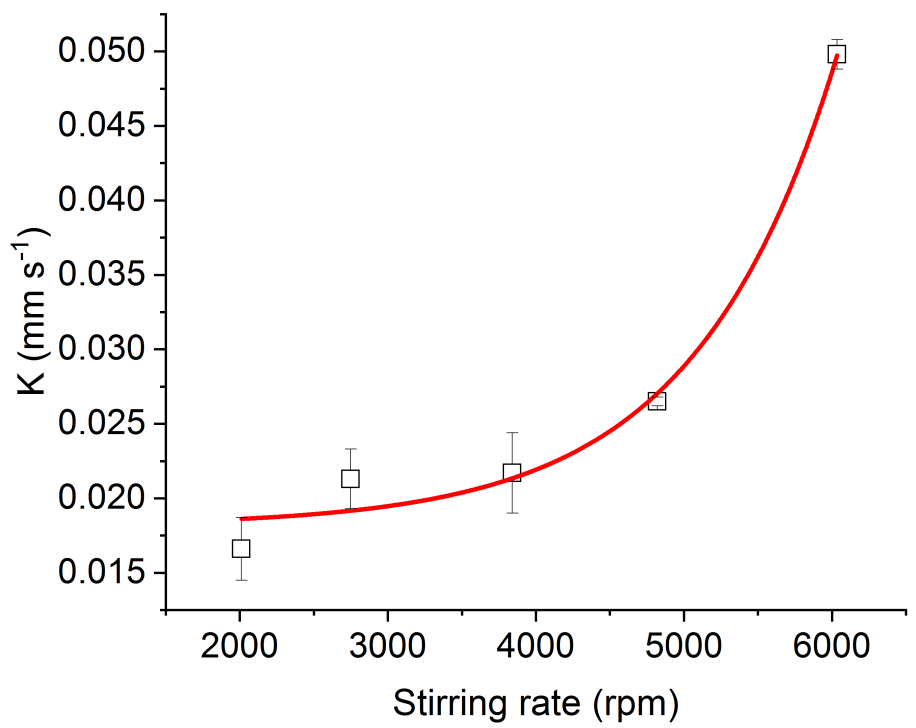

Figure 4. Values of $K$ at different stirring rates. The exponential line has been inserted to highlight the trend.

For a stirring rate greater than $4800 \mathrm{rpm}$, the mass transfer rate increases significantly probably because of the development of turbulent flows at the droplet/bulk interface. As reported in Table A1, the value of $K_{v}$ also rises with the stirring, as expected. In order to simulate a stagnant pool of contaminants stratified under groundwater, a stirring rate of $2010 \mathrm{rpm}$ (corresponding to $4.2 \mathrm{~m} / \mathrm{s}$ for the stirrer having a radius of $0.2 \mathrm{~cm}$ ) has been chosen for all the experiments with surfactants. To prove that TCE quickly reaches a homogeneous distribution in the water phase during the dissolution process, we performed an experiment by dissolving a drop $(5 \mu \mathrm{L})$ of a water-soluble dye (ferroin $25 \mathrm{mM}$ ), having a diffusivity similar to TCE $\left(D_{\mathrm{TCE}}=8.16 \times 10^{-6} \mathrm{~cm}^{2} \mathrm{~s}^{-1}[5], D_{\mathrm{Fe}}=7 \times 10^{-6} \mathrm{~cm}^{2} \mathrm{~s}^{-1}\right.$ [40]), into the stirred reactor $(2010 \mathrm{rpm})$ filled with $18 \mathrm{~mL}$ of water; we then measured the time employed to reach the equilibrium concentration in the bulk $(0.007 \mathrm{mM})$. We found that the system concentration reached the theoretical plateau value in $150 \mathrm{~s}$ (see Figure A1 in Appendix B), which is a very short time if compared with that taken for the complete 
dissolution of the TCE pool (11,000 s for a volume 10 times smaller) and with our sampling time (600 s). Therefore, we can consider that TCE reaches a homogeneous distribution in the bulk fast enough to model the process by ODEs.

As showed in Figure 5a and reported in Table A2 in Appendix A, the two surfactants have a similar effect on TCE mass transfer rate across the interface, with a minimal deviation of the maximum rate peak. In detail, SYN91/5 is more efficient in the concentration range $0.05-0.1 \mathrm{M}$, whereas SYN91/10 in the range $0.08-0.1 \mathrm{M}$, with $30-40 \%$ increase in mass transfer rate compared to water. Under the CMC, the mass transfer is comparable with pure water for both the surfactants. In contrast, the kinetics of dissolution is strongly inhibited at high tested concentrations of surfactants, becoming a rate slower than in water. This result might appear in contrast with the enhanced solubility of TCE measured at high surfactant concentrations (Table 1); however, it is worth noting that $K$ measures the speed at which a molecule of TCE crosses the interface and moves freely in the bulk. The net TCE flux across the interface $(d n / d t)$, measured in terms of mass (number of TCE molecules) per time, and driven by $\Delta C_{i}$, is always greater in the presence of surfactants with respect to pure water, as reported in Figure 5b,c. In other words, when the surfactants are present at high concentrations, the aggregates they form in solution are larger and can dissolve more TCE molecules, but, as a drawback, move slower into the bulk. Such a limitation was pointed out by several authors that found the aqueous micellar diffusion to be potential rate-limiting steps in interphase mass transfer [41-44]. In the case of SYN91/5, we could confirm a slowing effect of the micelles by comparing the TCE diffusion coefficients in pure water at $25^{\circ} \mathrm{C}\left(D=8.16 \times 10^{-6} \mathrm{~cm}^{2} \mathrm{~s}^{-1}\right.$ [5] $)$ with the diffusivity of SYN91/5 found to be in the range of $\sim 5 \times 10^{-7}-\sim 2 \times 10^{-6} \mathrm{~cm}^{2} \mathrm{~s}^{-1}$ at $25^{\circ} \mathrm{C}(0.01<[\mathrm{SYN} 91 / 5]<0.1 \mathrm{M})$ [45].

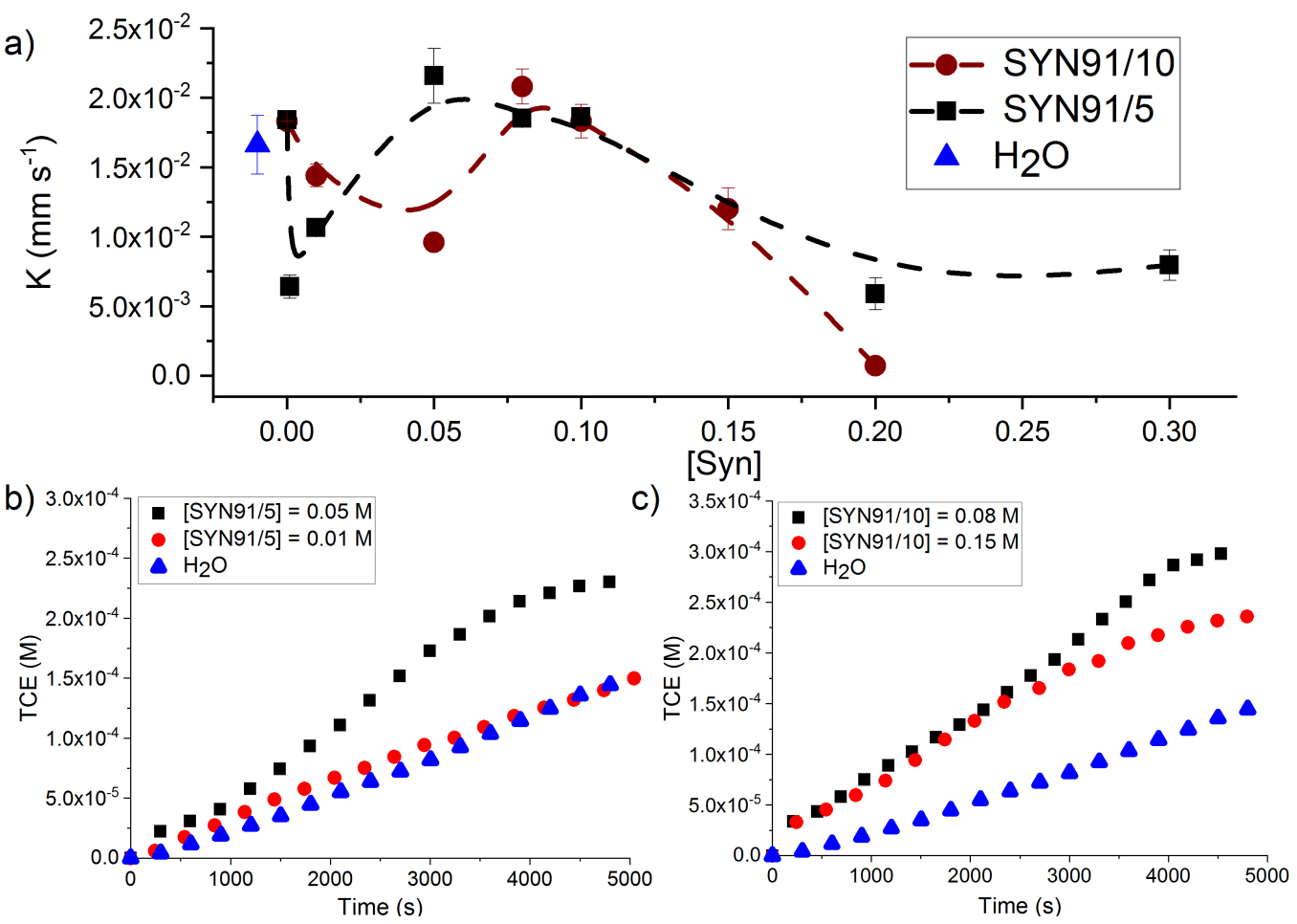

Figure 5. (a) Trend of $K$ in the presence of surfactants in the bulk compared with mass transfer rate in pure water. Lines are guides for the eye; $(\mathbf{b}, \mathbf{c})$ dissolution dynamics of a TCE droplet in the presence and in the absence of surfactants for SYN91/5 and SYN91/10, respectively.

\section{Conclusions}

The fate of DNAPLs in the environment and the consequential remediation problems have been intensively studied over the last 50 years. However, a scarce amount of literature is present about the mass transfer at the DNAPL/water interface. In the case of TCE, 
to the best of our knowledge, only one study exists where a value of mass transfer coefficient $K$ for the system TCE $/ \mathrm{H}_{2} \mathrm{O}$ can be found. Urynowicz and Siegrist [46] have found $K=6.98 \times 10^{-3} \mathrm{~mm} \mathrm{~s}^{-1}$ at $T=20^{\circ} \mathrm{C}$ at a stirring rate of $350 \mathrm{rpm}$, which, considering the different experimental conditions, is in line with our findings $\left(K=1.66 \times 10^{-2} \mathrm{~mm} \mathrm{~s}^{-1}\right.$ at $T=23^{\circ} \mathrm{C}$ and stirring rate $2010 \mathrm{rpm}$ ).

In this paper, we presented a fast and reliable method that allows for estimating the mass transfer coefficients in a system of two slightly miscible fluids. The analysis of $K$ trends permits, for example, to assess the efficiency of surfactants in transferring TCE from stagnant pools to the water bulk. In the specific case, we compared two ethoxylated alcohols belonging to the general class of Synperonic, to find that an optimal range exists where the presence of the surfactant effectively increases the mass transfer kinetics. The presence of a maximum in the $K$ trends of Figure 5 is related to the aggregation state of the surfactant in solution (micelles, liquid crystals, etc.), which, in turn, influences the mobility and diffusivity of the TCE in the bulk phase. The obtained results lead to the conclusion that the SYN91/ 5 would be a better choice for groundwater remediation because it is more efficient than SYN91/10 at lower concentrations. The knowledge of $K$ in specific environmental conditions would also help the optimization of in situ remediation strategies based on oxidation reactions (Reaction (1)).

Another interesting effect of surfactant presence is the significant decrease of the volatilization coefficient. This phenomenon is related to the lower air/bulk partition coefficient in the presence of micellar systems [47]. In environmental terms, this would help to prevent the dispersion of TCE into the atmosphere during remediation activity.

Author Contributions: Conceptualization, F.R. and N.V.; methodology, F.R. and N.V.; software, N.V.; validation, M.A.B., I.L., N.M., and M.S.-D.; formal analysis, F.R. and N.V.; investigation, N.V.; resources, F.R. and M.S.-D.; writing-original draft preparation, N.V. and F.R.; writing-review and editing, F.R., M.A.B., I.L., N.M., and M.S.-D.; supervision, F.R. All authors have read and agreed to the published version of the manuscript.

Funding: This research received no external funding.

Data Availability Statement: Data of SYN91/5 diffusivities reported in the unpublished Ref. [45] are available upon request to the corresponding author.

Acknowledgments: We thank Croda Inc. for gifting us with surfactants. Claudia Magrini and Leonardo Stiaccini are gratefully acknowledged for experimental support.

Conflicts of Interest: The authors declare no conflict of interest.

\section{Appendix A. Tables}

Table A1. $K$ and $K_{v}$ values at different stirring rates (CI, confidence interval; CC, correlation coefficient).

\begin{tabular}{cccccc}
\hline $\begin{array}{c}\text { Stirring } \\
(\mathbf{r p m})\end{array}$ & $\begin{array}{c}\boldsymbol{K} \\
\left(\mathbf{m m ~ s} \mathbf{- 1}^{-\mathbf{1}}\right.\end{array}$ & $\begin{array}{c}\mathbf{9 5 \%} \\
\mathbf{C I}\end{array}$ & $\begin{array}{c}\boldsymbol{K}_{\boldsymbol{v}} \\
\left(\mathbf{s}^{-\mathbf{1}}\right)\end{array}$ & $\begin{array}{c}\mathbf{9 5 \%} \\
\mathbf{C I}\end{array}$ & $\begin{array}{c}\mathbf{K} / \boldsymbol{K}_{\boldsymbol{v}} \\
\mathbf{C C}\end{array}$ \\
\hline 2010 & $(1.7 \pm 0.2) \times 10^{-2}$ & $2.06 \times 10^{-3}$ & $(6.0 \pm 0.2) \times 10^{-5}$ & $2.12 \times 10^{-5}$ & 0.956 \\
2750 & $(2.1 \pm 0.2) \times 10^{-2}$ & $1.96 \times 10^{-3}$ & $(6.0 \pm 0.1) \times 10^{-5}$ & $1.56 \times 10^{-5}$ & 0.767 \\
3840 & $(2.1 \pm 0.2) \times 10^{-2}$ & $2.68 \times 10^{-3}$ & $(9.3 \pm 0.1) \times 10^{-5}$ & $1.02 \times 10^{-6}$ & 0.888 \\
4820 & $(2.65 \pm 0.03) \times 10^{-2}$ & $2.94 \times 10^{-4}$ & $(9.7 \pm 0.1) \times 10^{-5}$ & $1.42 \times 10^{-6}$ & 0.922 \\
6034 & $(4.9 \pm 0.1) \times 10^{-2}$ & $9.26 \times 10^{-4}$ & $(1.1 \pm 0.1) \times 10^{-4}$ & $1.48 \times 10^{-5}$ & 0.899 \\
\hline
\end{tabular}


Table A2. Mass transfer coefficients $K$ and volatilization coefficients $K_{v}$ at different concentrations of SYN/X (CI, confidence interval; CC, correlation coefficient).

\begin{tabular}{|c|c|c|c|c|c|c|}
\hline System & $\begin{array}{c}\text { SYN } \\
(\mathrm{M})\end{array}$ & $\begin{array}{c}K \\
\left(\mathrm{~mm} \mathrm{~s}^{-1}\right)\end{array}$ & $\begin{array}{c}95 \% \\
\text { CI }\end{array}$ & $\begin{array}{c}K_{v} \\
\left(s^{-1}\right)\end{array}$ & $\begin{array}{c}95 \% \\
\text { CI }\end{array}$ & $\begin{array}{c}K / K_{v} \\
\mathrm{CC}\end{array}$ \\
\hline $\mathrm{H}_{2} \mathrm{O}$ & - & $(1.7 \pm 0.2) \times 10^{-2}$ & $2.06 \times 10^{-3}$ & $(6.0 \pm 0.2) \times 10^{-5}$ & $2.12 \times 10^{-5}$ & 0.956 \\
\hline SYN91/5 & $\begin{array}{c}1 \times 10^{-4} \\
1 \times 10^{-3} \\
0.01 \\
0.05 \\
0.08 \\
0.10 \\
0.20 \\
0.30\end{array}$ & $\begin{array}{c}(1.84 \pm 0.03) \times 10^{-2} \\
(6.4 \pm 0.8) \times 10^{-3} \\
(1.06 \pm 0.01) \times 10^{-2} \\
(2.1 \pm 0.1) \times 10^{-2} \\
(1.85 \pm 0.02) \times 10^{-2} \\
(1.86 \pm 0.01) \times 10^{-2} \\
(5.9 \pm 0.1) \times 10^{-3} \\
(7.9 \pm 0.6) \times 10^{-3}\end{array}$ & $\begin{array}{c}2.99 \times 10^{-4} \\
8.42 \times 10^{-4} \\
8.83 \times 10^{-5} \\
1.98 \times 10^{-3} \\
2 \times 10^{-4} \\
1.01 \times 10^{-4} \\
1.15 \times 10^{-3} \\
1.09 \times 10^{-3}\end{array}$ & $\begin{array}{c}- \\
(2.3 \pm 0.1) \times 10^{-4} \\
(2.9 \pm 0.2) \times 10^{-5} \\
(7.1 \pm 0.8) \times 10^{-5} \\
(3.4 \pm 0.5) \times 10^{-5} \\
(2.8 \pm 0.2) \times 10^{-4} \\
(4.2 \pm 0.1) \times 10^{-5} \\
(2.4 \pm 0.2) \times 10^{-4}\end{array}$ & $\begin{array}{c}- \\
9.8 \times 10^{-5} \\
2.02 \times 10^{-6} \\
1.37 \times 10^{-5} \\
8.54 \times 10^{-6} \\
1.96 \times 10^{-5} \\
1.26 \times 10^{-5} \\
1.96 \times 10^{-4}\end{array}$ & $\begin{array}{l}- \\
0.886 \\
0.802 \\
0.758 \\
0.952 \\
0.793 \\
0.897 \\
0.945\end{array}$ \\
\hline SYN91/10 & $\begin{array}{c}1 \times 10^{-4} \\
0.01 \\
0.05 \\
0.08 \\
0.10 \\
0.15 \\
0.20\end{array}$ & $\begin{array}{c}(1.83 \pm 0.01) \times 10^{-2} \\
(1.44 \pm 0.08) \times 10^{-2} \\
(9.59 \pm 0.02) \times 10^{-3} \\
(2.0 \pm 0.1) \times 10^{-2} \\
(1.8 \pm 0.1) \times 10^{-2} \\
(1.20 \pm 0.01) \times 10^{-2} \\
(7.1 \pm 0.1) \times 10^{-4}\end{array}$ & $\begin{array}{l}1.15 \times 10^{-5} \\
8.00 \times 10^{-4} \\
2.00 \times 10^{-5} \\
1.25 \times 10^{-3} \\
1.21 \times 10^{-3} \\
1.15 \times 10^{-3} \\
1.75 \times 10^{-5}\end{array}$ & $\begin{array}{c}(4.2 \pm 0.1) \times 10^{-5} \\
- \\
- \\
(5.0 \pm 0.5) \times 10^{-5} \\
- \\
(2.5 \pm 0.1) \times 10^{-5} \\
(9.5 \pm 0.5) \times 10^{-5}\end{array}$ & $\begin{aligned} 1.25 & \times 10^{-6} \\
& - \\
& - \\
5.59 & \times 10^{-6} \\
- & \\
1.68 & \times 10^{-6} \\
3.48 & \times 10^{-6}\end{aligned}$ & $\begin{array}{c}- \\
- \\
0.717 \\
- \\
0.861 \\
0.916\end{array}$ \\
\hline
\end{tabular}

\section{Appendix B. Ferroin Dissolution}

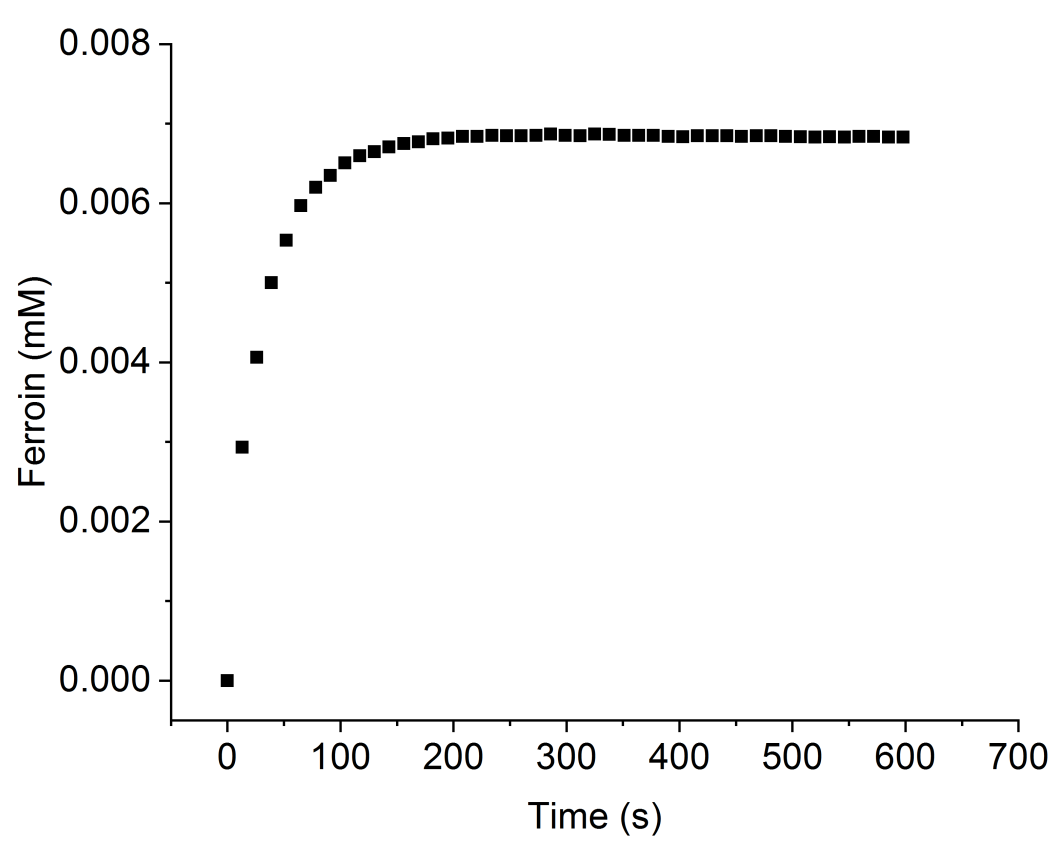

Figure A1. Dissolution of $5 \mu \mathrm{L}$ of ferroin $25 \mathrm{mM}$ in $18 \mathrm{~mL}$ of water at $2010 \mathrm{rpm}$.

\section{References}

1. Cichocki, J.A.; Guyton, K.Z.; Guha, N.; Chiu, W.A.; Rusyn, I.; Lash, L.H. Target Organ Metabolism, Toxicity, and Mechanisms of Trichloroethylene and Perchloroethylene: Key Similarities, Differences, and Data Gaps. J. Pharmacol. Exp. Ther. 2016, 359, 110-123. [CrossRef]

2. Schaerlaekens, J.; Vanderborght, J.; Merckx, R.; Feyen, J. Surfactant enhanced solubilization of residual trichloroethene: An experimental and numerical analysis. J. Contam. Hydrol. 2000, 46, 1-16. [CrossRef]

3. Schwille, F. Dense Chlorinated Solvents in Porous and Fractured Media: Model Experiments; Lewis Publishers: Chelsea, MI, USA, 1988.

4. Pennell, K.D.; Adinolfi, A.M.; Abriola, L.M.; Diallo, M.S. Solubilization of dodecane, tetrachloroethylene, and 1, 2-dichlorobenzene in micellar solutions of ethoxylated nonionic surfactants. Environ. Sci. Technol. 1997, 31, 1382-1389. [CrossRef] 
5. Rossi, F.; Cucciniello, R.; Intiso, A.; Proto, A.; Motta, O.; Marchettini, N. Determination of the trichloroethylene diffusion coefficient in water. AIChE J. 2015, 61, 3511-3515. [CrossRef]

6. Mulligan, C.; Yong, R.; Gibbs, B. Surfactant-enhanced remediation of contaminated soil: A review. Eng. Geol. 2001, 60, 371-380.

7. Intiso, A.; Miele, Y.; Marchettini, N.; Proto, A.; Sánchez-Domínguez, M.; Rossi, F. Enhanced solubility of trichloroethylene (TCE) by a poly-oxyethylene alcohol as green surfactant. Environ. Technol. Innov. 2018, 12, 72-79. [CrossRef]

8. Garza-Arévalo, J.I.; Intiso, A.; Proto, A.; Rossi, F.; Sanchez-Dominguez, M. Trichloroethylene solubilization using a series of commercial biodegradable ethoxylated fatty alcohol surfactants. J. Chem. Technol. Biotechnol. 2019, 94, 3523-3529. [CrossRef]

9. EPA Development Office of Research. In-Situ Chemical Oxidation-Engineering Issue. 2011. Available online: https://cfpub.epa. gov/si/si_public_record_report.cfm?Lab=NRMRL\&dirEntryId=156513 (accessed on 7 July 2021).

10. Farrell, J.; Kason, M.; Melitas, N.; Li, T. Investigation of the Long-Term Performance of Zero-Valent Iron for Reductive Dechlorination of Trichloroethylene. Environ. Sci. Technol. 2000, 34, 514-521. [CrossRef]

11. Cucciniello, R.; Intiso, A.; Castiglione, S.; Genga, A.; Proto, A.; Rossi, F. Total oxidation of trichloroethylene over mayenite $\left(\mathrm{Ca}_{1} 2 \mathrm{Al}_{1} 4 \mathrm{O}_{3} 3\right)$ catalyst. Appl. Catal. B Environ. 2017, 204, 167-172. [CrossRef]

12. Intiso, A.; Martinez-Triguero, J.; Cucciniello, R.; Rossi, F.; Palomares, A.E. Influence of the synthesis method on the catalytic activity of mayenite for the oxidation of gas-phase trichloroethylene. Sci. Rep. 2019, 9, 425. [CrossRef] [PubMed]

13. Intiso, A.; Martinez-Triguero, J.; Cucciniello, R.; Proto, A.; Palomares, A.E.; Rossi, F. A Novel Synthetic Route to Prepare High Surface Area Mayenite Catalyst for TCE Oxidation. Catalysts 2019, 9, 27. [CrossRef]

14. Cucciniello, R.; Intiso, A.; Siciliano, T.; Palomares, A.E.; Martínez-Triguero, J.; Cerrillo, J.L.; Proto, A.; Rossi, F. Oxidative Degradation of Trichloroethylene over $\mathrm{Fe}_{2} \mathrm{O}_{3}$-doped Mayenite: Chlorine Poisoning Mitigation and Improved Catalytic Performance. Catalysts 2019, 9, 747. [CrossRef]

15. Paria, S. Surfactant-enhanced remediation of organic contaminated soil and water. Adv. Colloid Interface Sci. 2008, 138, 24-58. [CrossRef] [PubMed]

16. Lominchar, M.A.; Lorenzo, D.; Romero, A.; Santos, A. Remediation of soil contaminated by PAHs and TPH using alkaline activated persulfate enhanced by surfactant addition at flow conditions. J. Chem. Technol. Biotechnol. 2018, 93, 1270-1278. [CrossRef]

17. Besha, A.T.; Bekele, D.N.; Naidu, R.; Chadalavada, S. Recent advances in surfactant-enhanced In-Situ Chemical Oxidation for the remediation of non-aqueous phase liquid contaminated soils and aquifers. Environ. Technol. Innov. 2018, 9, 303-322. [CrossRef]

18. Huo, L.; Liu, G.; Yang, X.; Ahmad, Z.; Zhong, H. Surfactant-enhanced aquifer remediation: Mechanisms, influences, limitations and the countermeasures. Chemosphere 2020, 252, 126620. [CrossRef]

19. Sun, Y.; Li, M.; Gu, X.; Danish, M.; Shan, A.; Ali, M.; Qiu, Z.; Sui, Q.; Lyu, S. Mechanism of surfactant in trichloroethene degradation in aqueous solution by sodium persulfate activated with chelated-Fe(II). J. Hazard. Mater. 2021, 407, 124814. [CrossRef]

20. Rossi, F.; Liveri, M.L.T. Chemical self-organization in self-assembling biomimetic systems. Ecol. Model. 2009, 220 , 1857-1864. [CrossRef]

21. Budroni, M.A.; Riolfo, L.A.; Lemaigre, L.; Rossi, F.; Rustici, M.; De Wit, A. Chemical Control of Hydrodynamic Instabilities in Partially Miscible Two-Layer Systems. J. Phys. Chem. Lett. 2014, 5, 875-881. [CrossRef]

22. Griffiths, R.W. Layered double-diffusive convection in porous media. J. Fluid Mech. 1981, 102, 221-248. 1002619. [CrossRef]

23. Budroni, M.; Carballido-Landeira, J.; Intiso, A.; De Wit, A.; Rossi, F. Interfacial hydrodynamic instabilities driven by cross-diffusion in reverse microemulsions. Chaos Interdiscip. J. Nonlinear Sci. 2015, 25, 064502. [CrossRef] [PubMed]

24. Budroni, M.A.; Lemaigre, L.; De Wit, A.; Rossi, F. Cross-diffusion-induced convective patterns in microemulsion systems. Phys. Chem. Chem. Phys. 2015, 17, 1593-1600. [CrossRef] [PubMed]

25. Budroni, M.A. Cross-diffusion-driven hydrodynamic instabilities in a double-layer system: General classification and nonlinear simulations. Phys. Rev. E 2015, 92, 063007. [CrossRef] [PubMed]

26. D'Hernoncourt, J.; Zebib, A.; De Wit, A. On the classification of buoyancy-driven chemo-hydrodynamic instabilities of chemical fronts. Chaos 2007, 17, 013109. [CrossRef] [PubMed]

27. Budroni, M.A.; De Wit, A. Dissipative structures: From reaction-diffusion to chemo-hydrodynamic patterns. Chaos Interdiscip. J. Nonlinear Sci. 2017, 27, 104617. [CrossRef] [PubMed]

28. Epstein, P.S.; Plesset, M.S. On the stability of gas bubbles in liquid-gas solutions. J. Chem. Phys. 1950, 18, 1505-1509. [CrossRef]

29. Duncan, P.B.; Needham, D. Microdroplet Dissolution into a Second-Phase Solvent Using a Micropipet Technique: Test of the Epstein-Plesset Model for an Aniline-Water System. Langmuir 2006, 22, 4190-4197. [CrossRef] [PubMed]

30. Su, J.T.; Needham, D. Mass Transfer in the Dissolution of a Multicomponent Liquid Droplet in an Immiscible Liquid Environment. Langmuir 2013, 29, 13339-13345. [CrossRef]

31. Lohse, D.; Zhang, X. Surface nanobubbles and nanodroplets. Rev. Mod. Phys. 2015, 87, 981-1035. [CrossRef]

32. Zhang, J.M.; Chen, Y.; Lohse, D.; Marin, A. Dissolution of microdroplets in a sparsely miscible liquid confined by leaky walls. J. Fluid Mech. 2021, 912. [CrossRef]

33. Cussler, E.L. Diffusion: Mass Transfer in Fluid Systems; Cambridge University Press: Cambridge, UK, 2009.

34. Pant, P.; Allen, M.; Cai, Y.; Jayachandran, K.; Chen, Y. Influence of physical factors on trichloroethylene evaporation from surface water. Water Air Soil Pollut. 2007, 183, 153-163. [CrossRef] 
35. Teng, H.; Yamasaki, A. Dissolution of $\mathrm{CO}_{2}$ droplets in the ocean. Energy 1997, 22, 751-761. [CrossRef]

36. Collins, T.J. ImageJ for microscopy. BioTechniques 2007, 43, S25-S30. [CrossRef] [PubMed]

37. Levenberg, K. A method for the solution of certain nonlinear problems in least squares. Q. Appl. Math. 1944, 2, 164-168. [CrossRef]

38. Marquardt, D.W. An algorithm for least-squares estimation of nonlinear parameters. J. Soc. Ind. Appl. Math. 1963, 11, 431-441. [CrossRef]

39. Hoops, S.; Sahle, S.; Gauges, R.; Lee, C.; Pahle, J.; Simus, N.; Singhal, M.; Xu, L.; Mendes, P.; Kummer, U. COPASI-A COmplex PAthway SImulator. Bioinformatics 2006, 22, 3067-3074. [CrossRef]

40. Tomasi, R.; Noel, J.M.; Zenati, A.; Ristori, S.; Rossi, F.; Cabuil, V.; Kanoufi, F.; Abou-Hassan, A. Chemical communication between liposomes encapsulating a chemical oscillatory reaction. Chem. Sci. 2014, 5, 1854-1859. [CrossRef]

41. Pennell, K.D.; Abriola, L.M.; Weber, W.J., Jr. Surfactant-enhanced solubilization of residual dodecane in soil columns. 1. Experimental investigation. Environ. Sci. Technol. 1993, 27, 2332-2340. [CrossRef]

42. Grimberg, S.J.; Nagel, J.; Aitken, M.D. Kinetics of phenanthrene dissolution into water in the presence of nonionic surfactants. Environ. Sci. Technol. 1995, 29, 1480-1487. [CrossRef]

43. Johnson, J.C. Mass Transfer in Porous Media: The Effect of Surfactants on the Mass Transfer Rate Coefficient. Ph.D. Thesis, Princeton University, Princeton, NJ, USA, 1998.

44. Bolsman, T.; Veltmaat, F.; Van Os, N. The effect of surfactant structure on the rate of oil solubilization into aqueous surfactant solutions. J. Am. Oil Chem. Soc. 1988, 65, 280-283. [CrossRef]

45. Falsini, S.; Intiso, A.; Spinozzi, F.; Ristori, S.; Marchettini, N.; Garza-Arévalo, J.I.; Sanchez-Dominguez, M.; Rossi, F. PolyOxyethylene Alcohol as Green Surfactant for VOCs Remediation: Physico-Chemical Characterization. 2020, submitted.

46. Urynowicz, M.A.; Siegrist, R.L. Interphase mass transfer during chemical oxidation of TCE DNAPL in an aqueous system. J. Contam. Hydrol. 2005, 80, 93-106. [CrossRef] [PubMed]

47. Cohen, Y.; Ryan, P.A. Multimedia modeling of environmental transport: Trichloroethylene test case. Environ. Sci. Technol. 1985, 19, 412-417. [CrossRef] [PubMed] 